\title{
PESQUISA (AUTO)BIOGRÁFICA EM ANÁLISE: ENTRE DIÁLOGOS EPISTEMOLÓGICOS E TEÓRICO- METODOLÓGICOS
}

\section{Apresentação}

A pesquisa (auto)biográfica no campo educacional brasileiro vincula-se a uma rede de cooperação acadêmico-científica e internacional, contando, notadamente, com Laboratórios e Grupos de Pesquisa de países latino-americanos e europeus, que têm contribuído para significativos avanços no âmbito dos estudos (auto)biográficos. As diversas perspectivas de pesquisa e os modos próprios como os pesquisadores, situados histórico e espaço-temporalmente, a partir das apropriações epistemológicas e teórico-metodológicas do método (auto)biográfico, fazem emergir formas implicadas de produzir conhecimento. Trata-se de um movimento de pesquisa-ação-formação, que tem como centralidade os sujeitos, suas histórias individuais, coletivas, institucionais, de formação, de inserção social, de empoderamento, através das formas como acessam suas memórias, mediadas por experiências e narrativas sobre a vida, em suas múltiplas dimensões.

No conjunto dos estudos já realizados e em desenvolvimento, especialmente a vinculação às práticas de formação configuraram-se como uma entrada fecunda e fértil para a consolidação do movimento biográfico no Brasil, que teve, como marco inicial, o começo dos anos de 1990, abrindo-se, posteriormente, para uma multiplicidade de práticas de pesquisa, em diferentes Programas de Pós-graduação da área, mas também, em um diálogo interdisciplinar, com a sociologia, a antropologia, a antropologia filosófica, a história, a literatura e as artes, gerando os novos contornos que o domínio dos estudos (auto)biográficos tem conquistado no campo educacional.

Mapeamentos já realizados sobre a pesquisa (auto)biográfica no Brasil (BUENO et al, 2006; SOUZA et al, 2008; STEPANHOU, 2008; SOUZA; MIGNOT, 2015) 1 atestam o rastreamento, desde o ano de 1985 até 2015, dos diferentes contornos e formas que a pesquisa (auto)biográfica vem assumido, bem como de suas contribuições para a formação de professores, para os estudos sobre a história da profissão docente, das instituições escolares, as histórias de educadores(as), as histórias institucionais e individuais, face à produção e socialização de conhecimentos possibilitados pela memória, por experiências e narrativas.

O presente dossiê foi organizado com vistas a contribuir com outras possibilidades de análise da pesquisa (auto)biográfica e seus

1 Para mais informações, consultar: BUENO, Belmira Oliveira; CHAMLIAN, Helena Coharik; SOUSA, Cynthia Pereira de; CATANI, Denice Barbara. Histórias de vida e autobiografias na formação de professores e profissão docente (Brasil, 1985-2003). Educação e Pesquisa, São Paulo, v. 32, n. 2, p. 385-410, 2006. SOUZA, Elizeu Clementino de; SOUSA, Cynthia Pereira de.; CATANI, Denice Barbara. A pesquisa (auto)biográfica e a invenção de si no Brasil. Revista da FAEEBA - Educação e Contemporaneidade, Salvador, v. 17, n. 29, p. 31-42, jan./jun., 2008. STEPHANOU, Maria. Jogos de memórias nas esquinas dos tempos: territórios e práticas da pesquisa (auto)biográfica na pós-graduação em Educação no Brasil. In: SOUZA, Elizeu Clementino de.; PASSEGGI, Maria da Conceição. (Orgs.). Pesquisa (auto) biográfica: cotidiano, imaginário e memória. São Paulo: PAULUS; Natal: EDUFRN, 2008. p. 19-53. MIGNOT, Ana Chrystina; SOUZA, Elizeu Clementino de. Modos de viver, narrar e guardar: diálogos cruzados sobre pesquisa (auto)biográfica. Revista Linhas. Florianópolis, v. 16, n. 32, p. 10-33, set./dez. 2015. 
desafios epistemológicos e teórico-metodológicos. As análises aqui reunidas originam-se do desejo bem visivel dos autores de dialogar com os diversos modos de investigação e tecer sobre eles considerações, distanciamentos e aproximações, de ordem metodológica e epistemológica. Com isso, esperam dar a ver aos leitores e ao campo de pesquisa alguns "nós" de investigação, encontros e desencontros, tendências já consolidadas e sugestões vislumbradas, mas ainda pouco exploradas. Objetos instigantes de estudo estão aqui contemplados, tais como as narrativas em oficinas "socioafetivas" e "videobiografias" de crianças e adolescentes, em situação de vulnerabilidade, e a presença pouco conhecida da figura masculina na educação infantil. Três retomadas da produção acadêmica oferecem indícios do movimento do campo de investigação (auto)biográfico no país. Dois textos iluminam aspectos epistemológicos e hermenêuticos, através de entrevistas (auto)biográficas e as disposições de mediação e reflexividade biográfica que se articulam ao ato de narrar. Em todos eles, há reflexões sobre a natureza do conhecimento educacional que é produzido no próprio processo de pesquisa (auto)biográfica, assim como nos modos de apropriação de metodologias e sínteses teóricas, de outros espaços de saberes e de intervenções, que se entrecruzam a análises implicadas e distanciadas de diferentes objetos biográficos e modos de narrar a vida e sua complexidade.

Em Relatos de experiencia, en busca de un saber pedagógico, José Contreras Domingo indaga-se sobre a natureza do saber pedagógico que se expõe, ou que é produzido, no contexto mesmo do registro narrativo de experiências educativas. Como educadores, necessitamos aprofundar esta reflexão: tornar visiveis, identificar as possibilidades e prestar atenção às questões educativas que são postas no ato narrativo, quando envolve a experiência vivida.
Em seguida, podem ser lidos três exemplos da produção acadêmica, no âmbito da pesquisa (auto)biográfica, somando-se a outros que já realizados que estabeleceram o "estado da arte" dos estudos (auto)biográficos no país. Inês de Souza Bragança e Maria Helena Menna Barreto Abrahão, no artigo Abordagens teórico-metodológicas da formação de professores em dois tempos: olhares sobre o CIPA I (2004) e o CIPA V (2012), vislumbram as mudanças e tendências nos modos de produzir pesquisa, propor modelos de formação docente e perceber linhas de investigação ainda não percorridas, na distância do espaço-temporal de dois Congressos Internacionais de Pesquisa (Auto) biográfica (CIPA).

Sandra Novais Sousa, Jacira Helena do Valle Pereira Assis e Eliane Greice Davanço Nogueira, em Questões teórico-metodológicas da abordagem (auto)biográfica no VI CIPA, mapeiam perspectivas e direcionamentos epistemológicos dos autores que embasaram teoricamente a produção científica divulgada na última edição do Congresso Internacional de Pesquisa (Auto)Biográfica. Como resultados principais, apontaram a diversidade de conceitos e entendimentos dos pesquisadores quanto ao (auto)biográfico, sugerindo uma pluralidade de enfoques epistemológicos, que priorizam ora os aspectos sociológicos, ora os históricos ou psicológicos, no tratamento das narrativas e histórias de vida, nas pesquisas em educação. Observam, por outro lado, que um número, ainda reduzido, de pesquisadores se posicionam epistemologicamente, reivindicando um status de método para o (auto)biográfico.

Identidade e profissionalismo docente: contributos da investigação narrativa, analisa trabalhos de natureza empírica, realizados em Portugal e no Brasil, na área educacional, sobre identidade e profissionalismo docente, ancorados na pesquisa (auto)biográfica. Corroborando outros estudos, o mapeamento de- 
monstrou a grande diversidade de referenciais teóricos, de apropriações e aproximações à pesquisa (auto)biográfica, presentes nas perspectivas de investigadores de ambos os países. Para o caso brasileiro, foi possível identificar um número maior de investigações de caráter interventivo, com o uso de estratégias metodológicas que apostam na construção da identidade dos sujeitos-professores e nas investigações de pesquisa-formação.

Em Auto-hermenêutica em entrevistas autobiográficas, Patrícia Claudia da Costa analisa o que denomina de "alguns efeitos colaterais" provocados por entrevistas de natureza autobiográfica, tendo como base de dados 31 entrevistas, realizadas durante uma pesquisa sobre a trajetória de docentes universitários, sob a perspectiva inspiradora de Bourdieu. Conclui que o ato de falar de si corresponde a uma oportunidade de produção de conhecimentos de feição hermenêutica, à medida que o entrevistado reconhece a capacidade de reelaborar alguns aspectos de sua trajetória, reordenando os rumos da narrativa com base na reflexão sobre as condições reconhecidas no discurso produzido.

Abordando uma questão sensivel para os estudos educacionais, de vulnerabilidade e risco na infância e adolescência, em Videobiografias de exclusão na escuta de comportamentos desafiadores na escola, Cristóvão Pereira Souza e Maria da Conceição Passeggi discutem as dificuldades de aprendizagem e inadaptação escolar de crianças e adolescentes institucionalizados por medida protetiva de abrigo. Os referenciais teórico-metodológicos da pesquisa (auto)biográfica e da antropologia (Manter a letra maiúscula) visual apoiaram a produção de narrativas videobiográficas, roteirizadas pelas crianças e adolescentes, como autores, em torno das experiências de vida, antes e durante o acolhimento institucional. Os resultados sinalizam, como dizem os autores, para a necessidade de uma "escuta que atente para a riqueza humana e temporal dos trajetos desses meninos e meninas", observando-se "as táticas, resistências e valores por eles convocados na arte de viver a singularidade de suas exclusões".

Notas sobre narrativa como instrumento de intervenção em contexto de saúde infanto-juvenil, de Ruzia Chaouchar dos Santos, Naiana Marinho Gonçalves, Henrique Araujo Aragusuku e Daniela Barros da Silva Freire Andrade, acompanha o potencial da narrativa enquanto instrumento de intervenção psicológica em um CAPSI, a partir da apresentação de um estudo de caso individual. 0 estudo fundamentou-se na Teoria das Representações Sociais, em diálogo com a Teoria Histórico-Cultural e os Estudos sobre Narrativas. Em um primeiro momento, a narrativa constituiu-se em um discurso defensivo, pautado pelo modelo do estado de bem-estar, saúde e felicidade. No segundo momento, observou-se a emergência de narrativas espontâneas, liberadas das preocupações relativas ao protocolo de tratamento e anunciando conteúdos e conflitos, por meio de metáforas que deixam ver o processo de enfrentamento do desconhecido.

Alexandra Coelho Pena, em Histórias de vida de professores homens na educação infantil, chama a atenção para a necessidade de discutir a complexidade da presença masculina na educação de crianças de zero a cinco anos, em função do estranhamento por parte de professores, gestores e familiares, quanto à presença de docentes do sexo masculino nessa etapa da educação básica que, culturalmente, e historicamente, tem estreito laço com o feminino e o materno. Foram realizadas entrevistas de história de vida de professores da Educação Infantil, em instituições privadas e/ou públicas, com diferentes tempos de experiência profissional nesse segmento. Martin Buber, Mikhail Bakhtin e Walter Benjamin 
apoiam, como referências teóricas, a análise das histórias recolhidas.

As análises empreendidas pelos autores, ao tomarem, como referência, os modos como se apropriam do método (auto)biográfico, através de diálogos epistemológicos, teóricometodológicos e de diferentes perspectivas de análise, ampliam e marcam a diversidade de reflexões dos fenômenos (auto)biográficos, a variedade de fontes e aprofundamentos que o campo de pesquisa possibilita.

Esperamos que a socialização desse material favoreça outras reflexões, contribua para as pesquisas e práticas de formação que têm se desenvolvido cotidianamente nos nossos espaços de pesquisa-formação, abrindo-se e comportando novos objetos de estudo, temas, fontes e análises ancoradas na pesquisa (auto) biográfica.

Dislane Zerbinatti Moraes

Universidade de São Paulo

Elizeu Clementino de Souza Universidade do Estado da Bahia. 